\title{
INVOLVEMENT IN HOMEWORK THROUGHOUT THE GRADE LEVELS IN SECONDARY EDUCATION
}

\author{
Bibiana Regueiro ${ }^{1}$, Antonio Valle ${ }^{1}$, Susana Rodríguez ${ }^{1}$, Isabel Piñeiro ${ }^{1}$, \\ Iris Estévez ${ }^{2}$, \& Natalia Suárez ${ }^{3}$ \\ ${ }^{1}$ Department of Psychology, University of A Coruña (Spain) \\ ${ }^{2}$ Department of Pedagogy and Didactics, University of A Coruña (Spain) \\ ${ }^{3}$ Department of Psychology, University of Oviedo (Spain)
}

\begin{abstract}
Homework is one of those topics that have been constantly updated within the educational field. Not only is it an issue that has been debated permanently in different educational sectors, but opinions and attitudes were always very changing and polarized. It is somewhat paradoxical that while the relevance of homework increases as students' progress through the educational system, their involvement in homework tends to decrease. Thus, the present investigation tries to provide reliable information about changes in students' involvement in homework, as throughout the grades of Secondary Education. In addition, it is intended to know to what extent such changes relate to motivational and affective variables related to homework (intrinsic motivation, interest, perceived usefulness and anxiety) of the students themselves. A total of 899 students from 14 schools from three provinces in northern Spain participated in the study, whose ages range from 12 to 16. The data were analysed in two stages. The first stage was a multivariate analysis (MANCOVA) examining the relationship between the grade level (independent variable) and the three variables associated with involvement in homework (dependent variables). Prior performance and gender were introduced as covariables (for the purposes of statistical control). In the second stage, new covariables were added to the previous design, namely intrinsic motivation, interest, perceived usefulness and anxiety regarding homework. The results of this research indicate that, as the grade progresses, the involvement of students in homework gets worse: they do less homework, dedicate less time and use worse this time spent on homework because they do not understand what their purpose is. In addition, the girls spend more time doing homework despite the fact that, according to the results obtained in the present study, homework time management in girls is worse than boys.
\end{abstract}

Keywords: Homework, involvement, motivation, secondary education.

\section{Introduction}

Homework is one of the most controversial issues in education for many years. The issue is really important, but its high degree of complexity does not allow us a clear answer about its prescription.

Trautwein, Lüdtke, Schnyder and Niggli (2006) have proposed a theoretical model of homework in which elements of the expectancy-value theory (Eccles \& Wigfield, 2002), the self-determination theory (Deci \& Ryan, 2002), and research on learning and instruction (Brophy \& Good, 1986) are combined (Valle et al., 2015).

In this way, the variables directly related to the involvement of students in homework are determined by other variables of different nature like the motivational variables. The type of reasons or reasons that students have to do their homework, along with the degree of interest and the perceived usefulness they have of them, affect their degree of involvement (amount of homework done, time dedicated to them and use of that time) and, consequently, in their academic performance (Pan et. al., 2013). If the more students are involved, the better grades they obtain, then doing homework is better than not doing homework, and assigning homework in class will therefore contribute to improving students' academic performance (Suárez et al., 2019). But, how is this involvement throughout the grades? Thus, the present investigation tries to provide reliable information about changes in students' involvement in homework, as throughout the grades of Secondary Education. In addition, it is intended to know to what extent such changes relate to motivational and affective variables related to homework (intrinsic motivation, interest, perceived usefulness and anxiety) of the students themselves. 


\section{Method}

\subsection{Participants}

899 students from 14 schools from three provinces in northern Spain participated in the study, whose ages range from 12 to 16 . Of them, $24.1 \%$ were in their first year of compulsory secondary school $(n=217), 22.6 \%$ were in their second year $(n=203), 22.5 \%$ were in their third year $(n=202)$ and $30.8 \%$ were in their fourth year $(\mathrm{n}=277)$.

\subsection{Measures}

The data in this study were recognized by EDE (Homework Survey) and the following variables were evaluated: a) amount of homework done, b) time spent on homework, and c) homework time management. Each of these dimensions is composed of several items with a Likert scale with five alternatives (ranging from $1=$ none to $5=$ all).

In order to have information about motivational and affective variables linked to homework, information was collected on the following variables: a) intrinsic motivation towards homework; b) interest in homework; c) perception of usefulness of homework and d) anxiety. Each of these dimensions is composed of several items with a Likert scale with five alternatives (ranging from $1=$ none to $5=$ all).

Prior academic performance was obtained by the final qualifications obtained in Language, Foreign Language, and Mathematics.

\subsection{Procedure}

The data on the students' survey were collected in one class period during regular school hours by external staff, after obtaining the consent of the school directors and the students' teachers.

\subsection{Data analysis}

For the data analysis, MANCOVAs were first carried out, taking as an independent variable the grade and as dependent variables the three variables linked to the involvement in homework. Previous academic performance was introduced as a covariate. In the second stage, the motivational variables were incorporated as covariables, in addition to the previous performance. As an effect size measure, we used the partial eta-squared coefficient $\left(\eta_{\mathrm{p}}{ }^{2}\right)$. To interpret the effect sizes, we used the criterion established in the classic study by Cohen (1988), based on which the effect is small when $\eta_{\mathrm{p}}{ }^{2}=.01(d=.20)$, the effect is medium when $\eta_{\mathrm{p}}{ }^{2}=.059(d=.50)$ and the effect is large if $\eta_{\mathrm{p}}{ }^{2}=.138(d=.80)$.

\section{Results}

- Differences in involvement in homework by grade level

At a multivariate level, controlling for the effect of academic performance, the results show statistically significant differences in the variables associated with involvement in homework by grade level $\left(\lambda_{\text {Wilks }}=.895, F(9,2161)=11.19 ; p<.001, \eta_{\mathrm{p}}^{2}=.036\right)$ as well as by gender $\left(\lambda_{\text {Wilks }}=.958\right.$, $\left.F(3,888)=12.83 ; p<.001, \eta_{\mathrm{p}}^{2}=.042\right)$. The gender and grade level interaction is not statistically significant. The effect sizes are small. As expected, prior academic performance is significantly related to the set of variables associated with involvement in homework $\left(\lambda_{\text {Wilks }}=.813, F(3,888)=68.14 ; p<.001, \eta_{\mathrm{p}}{ }^{2}=.187\right)$, with a large effect size, which explains much of the variance in the dependent variables: amount of homework donde $\left(F(1,890)=193.57, p<.001, \eta_{\mathrm{p}}^{2}=.179\right)$, time spent $(F(1,890)=18.60, p<.001$, $\left.\eta_{\mathrm{p}}^{2}=.020\right)$ and homework time management $\left(F(1,890)=41.83, p<.001, \eta_{\mathrm{p}}^{2}=.045\right)$.

Statistically controlling for the effect of prior academic performance, the results of the analysis indicated that there is still a significant amount of variance associated with grade level. Specifically, we observed the existence of statistically significant differences by grade level with regard to amount of homework done $\left(F(3,890)=31.60, p<.001, \eta_{\mathrm{p}}{ }^{2}=.096\right)$, homework time management $(F(3,890)=6.07$, $\left.p<.001, \eta_{\mathrm{p}}{ }^{2}=.020\right)$ and time spent on homework $\left(F(3,890)=3.43, p<.05, \eta_{\mathrm{p}}{ }^{2}=.011\right)$. The effect size is medium in the amount of homework completed and small in the other two variables. Likewise, we could also see statistically significant differences by gender with regard to homework time management $(F(1,890)$ $\left.=3.87, p<.05, \eta_{\mathrm{p}}{ }^{2}=.004\right)$ and time spent on homework $\left(F(1,890)=30.54, p<.001, \eta_{\mathrm{p}}{ }^{2}=.033\right)$, but not in amount of homework done. In this sense, despite the less amount of time spent on homework, boys make a better use of this time. The effect size is small. 


\section{- Relationship between involvement in homework, motivation and anxiety}

Controlling for the effect of academic performance and the motivational and affective variables included in the model, the results of the MANCOVA showed statistically significant differences by grade level in the three variables associated with involvement in homework taken as a whole $\left(\lambda_{\text {wilks }}=.924\right.$, $\left.F(9,2151)=7.92, p<.001, \eta_{\mathrm{p}}{ }^{2}=.026\right)$ and by gender with regard to the three variables associated with involvement in homework taken as a whole $\left(\lambda_{\text {Wilks }}=.965, F(3,884)=10.74, p<.001, \eta_{\mathrm{p}}^{2}=.026\right)$.

However, the effect size is small in both cases.

Just as in the previous model, prior academic performance is significantly related to all three variables associated with involvement in homework $\left(\lambda_{\text {Wilks }}=.846, F(3,884)=53.78, p<.001, \eta_{\mathrm{p}}{ }^{2}=.154\right)$, with a large effect size. Likewise, this relationship is also significant with each of the three variables taken individually: time spent on homework $\left(F(1,886)=15.26, p<.001, \eta_{\mathrm{p}}^{2}=.017\right)$, homework time management $\left(F(1,886)=20.80, p<.001, \eta_{\mathrm{p}}^{2}=.023\right)$ and amount of homework done $(F(1,886)=155.00, p<.001$, $\left.\eta_{\mathrm{p}}^{2}=.149\right)$.

With regard to the motivational and affective variables, the results indicate that they all predict a statistically significant amount of variance in the students' involvement in homework: intrinsic motivation $\left(\lambda_{\text {Wilks }}=.967, F(3,884)=9.93, p<.001, \eta_{\mathrm{p}}^{2}=.033\right)$, interest $\left(\lambda_{\text {Wilks }}=.982, F(3,884)=5.35, p<.001\right.$, $\left.\eta_{\mathrm{p}}{ }^{2}=.018\right)$, perceived usefulness $\left(\lambda_{\text {Wilks }}=.988, F(3,884)=3.48, p<.05, \eta_{\mathrm{p}}{ }^{2}=.012\right)$ and anxiety regarding homework $(\lambda \mathrm{Wilks}=.984, F(3,884)=4.88, p<.05, \eta \mathrm{p} 2=.016)$. In all cases, the effect size is small.

From a univariate standpoint, the four motivational and affective variables explain a statistically significant amount of variance in at least two of the three dependent variables related to the students' involvement in homework. Thus, we found that intrinsic motivation towards homework significantly explains the variability in the amount of homework completed $\left(F(1,886)=17.04, p<.001, \eta_{\mathrm{p}}{ }^{2}=.019\right)$ and in homework time management $\left(F(1,886)=17.71, p<.001, \eta_{\mathrm{p}}^{2}=.020\right)$; interest in homework is associated with all three dependent variables: amount of homework done $\left(F(1,886)=3.98, p<.05, \eta_{\mathrm{p}}^{2}=.004\right)$, time spent on homework $\left(F(1,886)=7.83, p<.01, \eta_{\mathrm{p}}^{2}=.009\right)$ and use of the time spent on homework $(F(1,886)$ $\left.=8.76, p<.01, \eta_{\mathrm{p}}^{2}=.010\right)$; the perceived usefulness of homework significantly explains the amount of homework done $\left(F(1,886)=7.40, p<.01, \eta_{\mathrm{p}}{ }^{2}=.008\right)$ and the time spent on homework $(F(1,886)=6.66$, $\left.p<.01, \eta_{\mathrm{p}}^{2}=.007\right)$; and anxiety towards homework significantly explains both the time spent on homework $\left(F(1,886)=5.76, p<.05, \eta_{\mathrm{p}}^{2}=.006\right)$ and the homework time management $(F(1,886)=6.37, p<.05$, $\left.\eta_{\mathrm{p}}^{2}=.007\right)$.

After having statistically controlled for the effect of prior performance and the motivational and affective variables, we must still explain a significant amount of variance associated with the grade level with regard to the amount of homework done $\left(F(3,886)=22.02, p<.001, \eta_{\mathrm{p}}{ }^{2}=.069\right)$, as well as the variance associated with gender in terms of time spent on homework $\left(F(1,886)=26.19, p<.001, \eta_{\mathrm{p}}{ }^{2}=.069\right)$ and of the use of this time $\left(F(1,886)=3.95, p<.05, \eta_{\mathrm{p}}{ }^{2}=.004\right)$, all of which have a medium effect size except the last one, which is small.

\section{Discussion}

The results of this research indicate that, as the grade progresses, the involvement of students in homework gets worse: they do less homework, dedicate less time and use worse this time spent on homework because they do not understand what their purpose is. In addition, the girls spend more time doing homework despite the fact that, according to the results obtained in the present study, homework time management in girls is worse than boys.

In line with other studies (e.g., Núñez et al., 2015), the data indicates that there is a downward tendency in the amount of homework completed, the use of the time and the amount of time spent on homework, even though this tendency is the clearest in terms of the amount of homework done (of the amount assigned by the teacher).

As expected based on previous research, girls seem to spend more time doing homework (Trautwein, 2007) even though, according to the results of this study, homework time management in girls is worse than boys.

About educational implications, in view of the results obtained in this study, it is necessary that students understand why it is necessary to do homework. Teachers must prescribe homework by clearly explaining the usefulness of homework. This way we will avoid that as the grade progresses, the motivational variables decrease and, therefore, so do the implication variables. 


\section{References}

Brophy, J., \& Good, T. (1986). Teacher behavior and student achievement. In M. Wittrock (Ed.), Handbook of research on teaching ( $3^{\text {a }}$ Ed., pp. 328-375). New York, NY: Macmillan.

Cohen, J. (1988). Statistical power analysis for the behavioral sciences ( $2^{\mathrm{a}}$ ed.). Hillsdale, NJ: Erlbaum.

Deci, E. L., \& Ryan, R. M. (2002). Hanbook of self-determination research. Rochester, New York, NY: The University of Rochester Press.

Eccles, J. S., \& Wigfield, A. (2002). Motivational beliefs, values, and goals. Annual Review of Psychology, $53,109-132$.

Núñez, J. C., Suárez, N., Cerezo, R., González-Pienda, J., Rosário, P., Mourão, R., \& Valle, A. (2015). Homework and academic achievement across Spanish Compulsory Education. Educational Psychology. An International Journal of Experimental Educational Psychology, 35, 726-746.

Pan, I., Regueiro, B., Ponte, B., Rodríguez, S., Piñeiro. I., \& Valle, A. (2013). Motivación, implicación en los deberes escolares y rendimiento académico. Aula Abierta, 41(3), 13- 22.

Suárez, N., Regueiro, B., Estévez, I., Ferradás, M.M., Guisande, M.A., \& Rodríguez, S. (2019). Individual precursors of student homework behavioral engagement: The role of intrinsic motivation, perceived homework utility and homework attitude. Frontiers in Psychology, 10:941.

Trautwein, U. (2007). The homework-achievement relation reconsidered: Differentiating homework time, homework frequency, and homework effort. Learning and Instruction, 17(3), 372-388.

Valle, A., Pan, I., Núñez, J., Rodríguez, S., Rosário, P., \& Regueiro, B. (2015). Multiple Goals and Homework Involvement in Elementary School Students. The Spanish Journal of Psychology, 18(81), $1-11$. 